\title{
An Investigation of Viscosities, Calorific Values and Densities of Binary Biofuel Blends
}

\author{
Sharzali Che Mat ${ }^{1,2,1}, M . Y$. Idroas ${ }^{1}, Y . H$. Teoh ${ }^{1}$ and M. F. Hamid ${ }^{1}$ \\ ${ }^{1}$ School of Mechanical Engineering, Engineering Campus, Universiti Sains Malaysia, 14300, Nibong \\ Tebal, Pulau Pinang, Malaysia \\ ${ }^{2}$ Faculty of Mechanical Engineering, Universiti Teknologi MARA Pulau Pinang, 13500, Permatang \\ Pauh, Pulau Pinang, Malaysia
}

\begin{abstract}
Straight vegetable oil (SVO) biofuel is a promising alternative to petroleum diesel fuel primarily due to its comparable physical properties to that of petroleum diesel fuel. However, the relatively higher viscosity of SVO limits its direct application in diesel engine. To resolve this issue, binary biofuel blends was introduced in this study to reduce the viscosity of SVO. In this work, a novel biofuel namely Melaleuca Cajuputi oil (MCO) was used and blended with refined palm oil (RPO). A total of four blends with the mixing ratios of $20 \%, 40 \%, 50 \%$ and $60 \%$ of MCO were prepared. Various key properties of dynamic viscosity, calorific value and density of the blends were measured and benchmarked against the biodiesel standards based on ASTM D6751. It was found that viscosity and density of the blends decreased with the increase of MCO fraction. Meanwhile, the calorific value of the blends increased linearly as the MCO fraction increased. The blend of 40RPO60MCO was found to have comparable key properties of viscosity, calorific value and density to those of petroleum diesel fuel and ASTM D6751 standard.
\end{abstract}

\section{Introduction}

Recently, straight vegetable oils (SVOs) are gaining popularity as an alternative fuel for diesel engine due to its similar physical properties to that of petroleum diesel fuel. In addition, SVO is renewable, non-toxic, biodegradable and contain no sulphur that make it as an attractive candidate to replace diesel fuel [1]. However, the direct use of SVO in diesel engine will lead to severe carbon deposit, fuel injector clog and rapid wears of fuel pump components. These issues are primarily associated with a high viscosity of SVO that dramatically alters fuel spray characteristics, atomization quality and volatility [2].

There are several methods used to reduce the viscosity of SVO, such as micro-emulsion, preheat, blending, and transesterification. Among these different methods, the

\footnotetext{
*Corresponding author: sharzalm@yahoo.com
} 
transesterification process is the most widely used to reduce the viscosity of SVO and convert triglycerides into fatty acid methyl ester (commonly known as biodiesel) and glycerol. Generally, the produced biodiesel has viscosity and other key properties close to petroleum diesel fuel [2]. However, this transesterification process involved with a complex yet expensive process where a specific equipment and instrumentation are required. Besides, the process also leads to a by-product formation of glycerol. This crude glycerol requires further expensive purification process to produce pure glycerol which has better value added product instead of crude glycerol [3].

Blending of SVO with other lower viscosity fuel was also found to be an effective and economical method to reduce its viscosity. This strategy has been studied by many researchers [4-6]. Generally, it was reported that engine fuelled with this blended fuel has comparable performance characteristics to those of diesel fuel, but with some penalties in brake specific fuel consumption (BSFC). Most of the authors have concluded that this is mainly associated with the low calorific value (CV) of the blend, which resulted in the reduction of engine performance and increase in BSFC. Meanwhile, on the bright side, NOx emission was reported to be slightly lower compared to diesel fuel.

Alcohol is another ingredient that is often used by researchers for blending with vegetable oil. Short-chain alcohols like ethanol and methanol are often used in the earlier studies [7-10]. These blends were found to reduce the viscosity and improve volatility of the vegetable oils, but the blends has limited miscibility [11]. Surfactant is required to be added into the blends to increase the miscibility and enhance the stability. Additionally, these alcohols have low cetane number and CV [12]. Thus, increase in the percentage of alcohol will lower the cetane number and CV of blended fuel. Recently, researchers have studied the blends of longer-chain alcohols like butanol and pentanol with SVO primarily due to their close properties to those of diesel fuel. Longer-chain alcohols has better CV, flash point, boiling point and cetane number as compared to short-chain alcohols. Moreover, Longer-chain alcohol is miscible with SVO thus, no additional surfactant is required to produce a stable blend [13]. Laza and Bereczky [14] analysed the properties of rapeseed oil (RSO) blended with higher alcohol (butanol and pentanol) at $10 \%$ and $20 \%$ by volume. They found that the viscosity, density, flash point, CV and cetane number of the blends were decreased as the percentage of alcohol increased. Viscosity of the blend also was found to be temperature dependent. Increase in temperature significantly decrease the viscosity. Another similar work is focussing with the blend of pongamia oil, ethanol and butanol and tested on diesel engine to analyse its performance and emissions [15]. It was reported that there was reduction in $\mathrm{NO}_{\mathrm{x}}$ but increased in $\mathrm{CO}$ and $\mathrm{HC}$ was observed. The blends also exhibit higher BSFC compared to diesel fuel.

Recently, a less viscous biofuel such as pine oil, eucalyptus and camphor oil has also gained interest among researchers. This is mainly due to their relatively low viscosity and high calorific value as compared to those of SVO. As shown in Table 1 is the key properties of these less viscous biofuels and benchmarked against the biodiesel standards based on ASTM D6751. It was reported that the blend of these biofuels either with diesel or biodiesel were able to reduce viscosity and enhance the CV of the blends [16-18]. Apparently, the viscosity, CV and density of the blended fuel are the key properties to be analysed carefully to ensure their compatibility as an engine fuel. Therefore, a novel less viscous biofuel namely Melaleuca Cajuputi oil (MCO) was first introduced in this study for blending with refined palm oil (RPO). In the present study, MCO was chosen largely due to its commercially available as well as its comparable properties to those of eucalyptus and camphor oil. In this research works, the main objective is to obtain the optimum blend of RPO and MCO through binary biofuel blend strategy. This strategy proposed of blending of high viscosity RPO with low viscosity $\mathrm{MCO}$ as a method to reduce the viscosity and enhance the volatility of the blend. 
Table 1. Various properties of less viscous biofuel [18-20].

\begin{tabular}{|c|c|c|c|c|c|}
\hline Property & $\begin{array}{c}\text { Eucalyptus } \\
\text { oil }\end{array}$ & Pine oil & $\begin{array}{c}\text { Camphor } \\
\text { oil }\end{array}$ & Diesel & $\begin{array}{c}\text { ASTM } \\
\text { D6751 }\end{array}$ \\
\hline $\begin{array}{c}\text { Kinematic viscosity } \\
\text { at } 40^{0} \mathrm{C}\left(\mathrm{mm}^{2} / \mathrm{s}\right)\end{array}$ & 2 & 1.3 & 1.9 & $3-4$ & $1.9-6.0$ \\
\hline $\begin{array}{c}\text { Gross Calorific value } \\
(\mathrm{MJ} / \mathrm{kg})\end{array}$ & 43.27 & 42.80 & 34.65 & $42.7-44.8$ & - \\
\hline $\begin{array}{c}\text { Density at } 15^{0} \mathrm{C} \\
\left(\mathrm{kg} / \mathrm{m}^{3}\right)\end{array}$ & $890-895.5$ & 875 & 894.2 & $822-880$ & 880 \\
\hline Flash point $\left({ }^{0} \mathrm{C}\right)$ & 54 & 52 & 50 & $50-74$ & $93 \mathrm{~min}$. \\
\hline Boiling point $\left({ }^{0} \mathrm{C}\right)$ & 175 & $150-180$ & - & $150-180$ & - \\
\hline
\end{tabular}

\section{Material and method}

\subsection{Material}

The test fuel of RPO used for the binary biofuel formulation was purchased from the local market meanwhile MCO was purchased from a private supplier. RPO is in liquid fraction at room temperature and have better cloud point as compared to crude palm oil. Besides, MCO has clear greenish liquid, low viscosity and highly volatile.

\subsection{Blending preparation}

Binary biofuels were prepared using RPO and MCO in volumetric percentage. Four blends at mixing ratios of 20\% (80RPO20MC0), 40\% (60RPO40MCO), 50\% (50RPOMCO50) and $60 \%$ (40RPO60MCO) of MCO with RPO were prepared. All blends were prepared without emulsifier or surfactant. To ensure homogeneity, each blend of RPO-MCO was mixed thoroughly with a magnetic stirrer. The prepared samples were stored in glass bottle and kept at ambient temperature. The samples were monitored for phase separation for a month at a regular time interval.

\subsection{Experimental}

Dynamic viscosity of RPO, MCO and their blends were measured using Brookfield DV-III rheometer. Viscosity properties will determine the quality of fuel atomization, spray characteristic and volatility of the fuel. The measurement was performed at $40^{\circ} \mathrm{C}$ and the temperature was maintained by means of water bath. The viscosity was measured three times and the average value was obtained. The kinematic viscosity can be calculated by dividing the dynamic viscosity with the density of the blends.

Calorific values of the samples were determined using an adiabatic oxygen bomb calorimeter, Nenken 1013-B, Japan. This experiment was conducted according to ASTM D240 standard. CV is a measured of energy content in the fuel. Essentially, fuel with low $\mathrm{CV}$ will lead to the increase in BSFC of the engine.

The density of the fuel samples was determined by dividing the weight of the biofuel with the volume determined using $25 \mathrm{ml}$ Gay-Lussac pycnometer. The measurement was taken at ambient temperature $\left(\sim 27^{\circ} \mathrm{C}\right)$. The pycnometer used is certified according to DIN ISO 3507. 


\section{Results and discussion}

\subsection{The Effect of MCO blend on viscosity}

Fuel viscosity is the major parameter that determine the ability of fluid to flow, atomization, spray characteristics and volatility of the fuel. The dynamic viscosity of neat $\mathrm{RPO}, \mathrm{MCO}$ and their blends were present in Table 2. A total of four different biofuel blends, 80RPO20MCO (80\%RPO, 20\% MCO), 60RPO40MCO (60\%RPO, 40\% CMO), 50RPO50MCO (50\% RPO, 50\% MCO) and 40RPO60MCO (40\% RPO, 60\% MCO) were prepared and tested. Obviously, neat RPO has the highest viscosity as compared to neat MCO. Method of blending high viscosity oil with low viscosity oil significantly reduce the viscosity of RPO-MCO blend. Specifically, biofuel blend with highest MCO percentage (i.e. 40RPO60MCO) has remarkably reduced the viscosity down to $5.5 \mathrm{mPas}$. Besides, the experimental results also indicate that the higher the percentage of $\mathrm{MCO}$ in the blend, the lower the dynamic viscosity was observed. Thus, the proposed strategy of blending of less viscous biofuel with high viscosity RPO can effectively reduce the viscosity of the blend. The reduction in viscosity would enhance the volatility, thus enhance the spray characteristic of the fuel. Figure 1 present the correlation between dynamic viscosity with the MCO fraction. This correlation can be modelled by the mathematical relationship obtained from regression analysis of measured values, as given in Eq. (1). This relationship is in the form of exponential regression that best approximates all the measured data. Note that the obtained $\mathrm{R}^{2}$ is 0.9986 , which indicate a good fit between measured data and the regression model. Thus, Eq. (1) can be used to predict the viscosity of the blends.

$$
v=34.535 e^{-0.03 x}
$$

Where $v$ is dynamic viscosity and $x$ is MCO fraction.

Table 2. Viscosity, calorific value and density of various RPO-MCO blends.

\begin{tabular}{|c|c|c|c|c|}
\hline Blends ratio & $\begin{array}{c}\text { Dynamic viscosity } \\
\text { at 40 }\end{array}$ & $\begin{array}{c}\text { Kinematic } \\
\text { (mPas) }\end{array}$ & $\begin{array}{c}\text { Calorific value } \\
\left.\text { viscosity } \mathbf{( m m}^{\mathbf{2}} \mathbf{s}\right)\end{array}$ & $\begin{array}{c}\text { Density } \\
(\mathbf{M g})\end{array}$ \\
\hline 100RPO & 36 & 39.8 & 40.25 & 904.3 \\
\hline 100MCO & 1.8 & 2.1 & 43.16 & 867.1 \\
\hline $\begin{array}{c}\text { 80RPO20MC } \\
\text { O }\end{array}$ & 18.2 & 20.3 & 40.64 & 897.5 \\
\hline $\begin{array}{c}\text { 60RPO40MC } \\
\text { O }\end{array}$ & 10.5 & 11.8 & 41.27 & 890.6 \\
\hline $\begin{array}{c}\text { 50RPO50MC } \\
\text { O }\end{array}$ & 8 & 9.0 & 41.53 & 887.2 \\
\hline $\begin{array}{c}\text { 40RPO60MC } \\
\text { O }\end{array}$ & 5.5 & 6.2 & 41.84 & 883.7 \\
\hline Diesel & - & $3-4$ & $43-45$ & $822-880$ \\
\hline ASTM D6751 & - & $1.9-6.0$ & - & 880 \\
\hline
\end{tabular}

${ }^{\mathrm{a}}$ calculated 


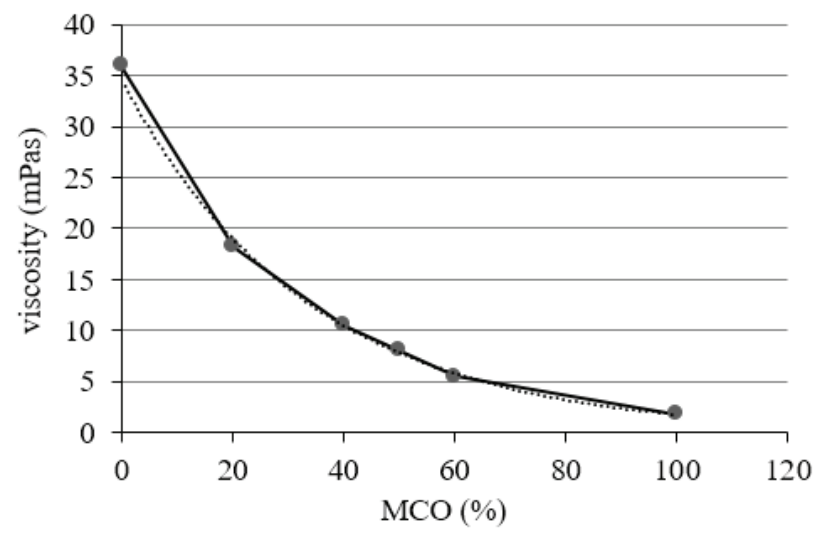

Fig. 1. The effect of RPO-MCO blends on dynamic viscosity.

\subsection{The Effect of MCO blend on calorific value}

Calorific values (CV) is an important parameter in the selection of a fuel. $\mathrm{CV}$ is the amount of heat released during the complete combustion of one gram of fuel. This value determines the chemical energy of the fuel which specify the combustion efficiency. Table 2 contains a description of the key properties of neat RPO, neat MCO and their blends. It can be observed that the CV of RPO was slightly lower compared to those of diesel fuel, but MCO interestingly has comparable CV to diesel fuel. As can be observed, the $\mathrm{CV}$ is directly increased as the percentage of MCO increased in the blends. Increase in $\mathrm{CV}$ is expected to improve the engine combustion efficiency, thus reduce the BSFC of the engine. Figure 2 present the correlation between $\mathrm{CV}$ with the MCO percentages. Mathematical model of the relationship is obtained in Eq. (2). Linear trendline with $\mathrm{R}^{2}$ value 0.9928 is the best fit to describe the measured data pattern. Eq. (2) can be used to predict the CV of the blends.

$$
C V=0.0295 x+40.121
$$

Where $C V$ is calorific value and $x$ is MCO fraction.

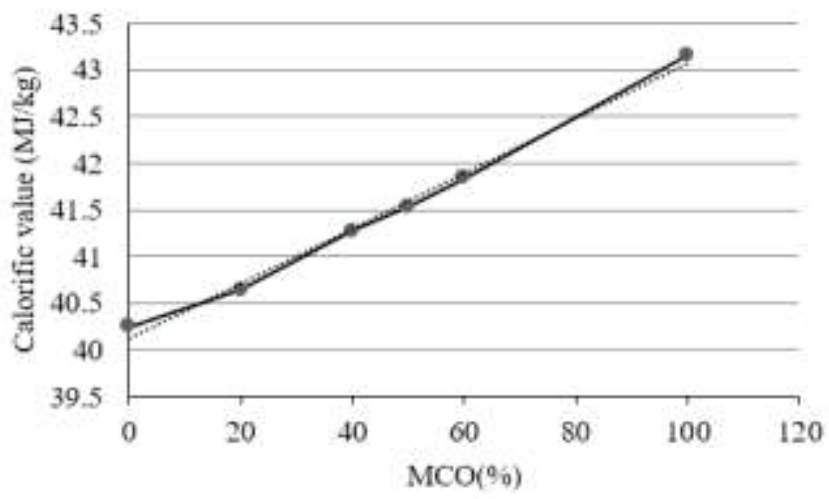

Fig. 2. The effect of RPO-MCO blends on calorific value. 


\subsection{The Effect of MCO blend on density}

Generally, fuel density are closely related to viscosity, CV and cetane number of the fuel [21]. Accordingly, any change in density will affect the performance of the engine. Data tabulated in Table 2 shows that the neat RPO has greater density compared to MCO and diesel fuel. Clearly, binary blend method of RPO-MCO decreases the density close to diesel fuel. Figure 3 present the correlation between density and the MCO fraction in the binary blends. Notably, the density of the blends linearly decreases with the increase of MCO in the blends. This relationship can be modelled by mathematical Eq. (3). The linear regression having $\mathrm{R}^{2}$ value of 0.9966 , which reflects a good fit of the line to the experimental data.

$$
\rho=905.05-0.3701 x
$$

Where $\rho$ is density and $x$ is MCO fraction.

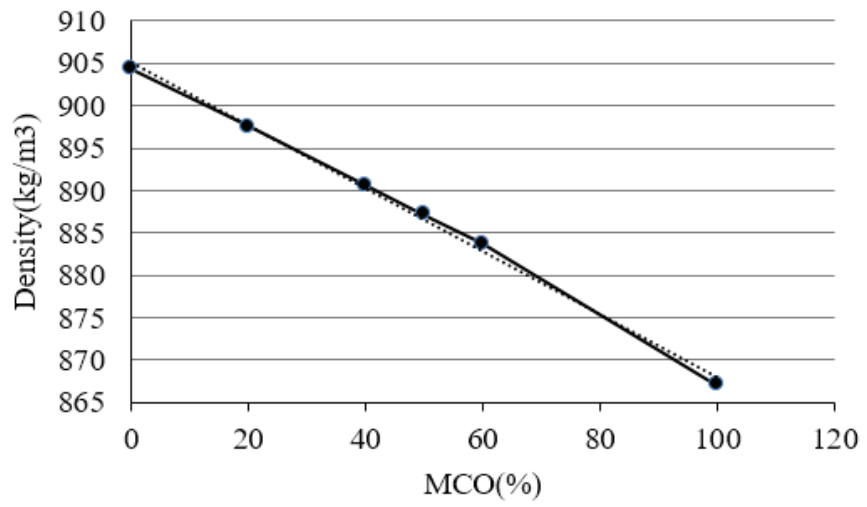

Fig. 3. The effect of RPO-MCO blends on density.

\section{Conclusions}

The key properties of dynamic viscosity, CV and density of binary biofuel blends (RPOMCO) were successfully analysed and benchmarked against the biodiesel standards based on ASTM D6751. In the present study, a total of three mathematical model were developed from the regression analysis of measured data to predict the dynamic viscosities, CVs and densities of RPO-MCO blends. Experimental data shows that viscosity of the blend was reduced with the increased of MCO percentage. Meanwhile, the $\mathrm{CV}$ of the blends was linearly increased as the percentage of MCO increased in the blends. Notably, the density of the blends linearly decreases with the increase of MCO in the blends. Analysis of these 3 key properties of the fuel suggested that the optimum blend of 40RPO60MCO was found comparable to diesel fuel. Therefore, binary biofuel blend of RPO-MCO can be considered as a potential biofuel to replace fossil diesel fuel. While this research project represents an initial step in the long-term goal of exploring a new biofuel source, more comprehensive analysis of other key physiochemical properties of the fuel blends will be required in the future. In this regard, more intense key properties of fuels will be measured to ensure the fuel blends can comply with the biodiesel standards based on ASTM D6751. 


\section{Acknowledgement}

We would like to acknowledge the financial support from Ministry of Higher Education Malaysia and Universiti Sains Malaysia under Fundamental Research Grant Scheme (FRGS/1/2016/TK07/USM/02/2; 203.PMEKANIK.6071356) and Research University Grant Scheme (project code of Mekanik/6071153).

\section{References}

[1] S.S. Sidibé, J. Blin, G. Vaitilingom, Y. Azoumah, Use of crude filtered vegetable oil as a fuel in diesel engines state of the art: Literature review, Renew. Sustain. Energy Rev. 14, 2748-2759 (2010)

[2] L.C. Meher, D. Vidya Sagar, S.N. Naik, Technical aspects of biodiesel production by transesterification - A review, Renew. Sustain. Energy Rev. 10, 248-268 (2006)

[3] M. Zhang, H. Wu, Effect of major impurities in crude glycerol on solubility and properties of glycerol/methanol/bio-oil blends, Fuel. 159, 118-127 (2015)

[4] C.D. Rakopoulos, K.A. Antonopoulos, D.C. Rakopoulos, D.T. Hountalas, E.G. Giakoumis, Comparative performance and emissions study of a direct injection Diesel engine using blends of Diesel fuel with vegetable oils or bio-diesels of various origins, Energy Convers. Manag. 47, 3272-3287 (2006)

[5] H. Hazar, H. Aydin, Performance and emission evaluation of a CI engine fueled with preheated raw rapeseed oil (RRO)-diesel blends, Appl. Energy. 87, 786-790 (2010)

[6] T.F. Yusaf, B.F. Yousif, M.M. Elawad, Crude palm oil fuel for diesel-engines: Experimental and ANN simulation approaches, Energy. 36, 4871-4878 (2011)

[7] M. Senthil Kumar, A. Ramesh, B. Nagalingam, An experimental comparison of methods to use methanol and Jatropha oil in a compression ignition engine, Biomass and Bioenergy. 25, 309-318 (2003)

[8] P.J. Singh, J. Khurma, A. Singh, Preparation, characterisation, engine performance and emission characteristics of coconut oil based hybrid fuels, Renew. Energy. 35, 2065-2070 (2010)

[9] S. Prabhakar, K. Annamalai, I.J. Lalvani, Experimental study of using hybrid vegetable oil blends in diesel engine, J. Sci. Ind. Res. 71, 612-615 (2012)

[10] S. Bhimani, J.L. Alvarado, K. Annamalai, C. Marsh, Emission characteristics of methanol-in-canola oil emulsions in a combustion chamber, Fuel. 113, 97-106 (2013)

[11] N. Arpornpong, C. Attaphong, A. Charoensaeng, D.A. Sabatini, S. Khaodhiar, Ethanol-in-palm oil/diesel microemulsion-based biofuel: Phase behavior, viscosity, and droplet size, Fuel. 132, 101-106 (2014)

[12] S. Kumar, J.H. Cho, J. Park, I. Moon, Advances in diesel-alcohol blends and their effects on the performance and emissions of diesel engines, Renew. Sustain. Energy Rev. 22, 46-72 (2013)

[13] B. Rajesh Kumar, S. Saravanan, Use of higher alcohol biofuels in diesel engines: A review, Renew. Sustain. Energy Rev. 60, 84-115 (2016)

[14] T. Laza, Á. Bereczky, Basic fuel properties of rapeseed oil-higher alcohols blends, Fuel. 90, 803-810 (2011)

[15] R. Senthil, E. Sivakumar, R. Silambarasan, Effect of butanol addition on performance and emission characteristics of a DI diesel engine fueled with pongamiaethanol blend., Int. J. ChemTech Res. 8, 459-467 (2015) 
[16] R. Vallinayagam, S. Vedharaj, W.M. Yang, P.S. Lee, K.J.E. Chua, S.K. Chou, Pine oil-biodiesel blends: A double biofuel strategy to completely eliminate the use of diesel in a diesel engine, Appl. Energy. 130, 466-473 (2014)

[17] S. Kommana, B. Naik Banoth, K. Radha Kadavakollu, Eucalyptus-Palm Kernel Oil Blends: A Complete Elimination of Diesel in a 4-Stroke VCR Diesel Engine, J. Combust. 2015, 1-7 (2015)

[18] G. Kasiraman, B. Nagalingam, M. Balakrishnan, Performance, emission and combustion improvements in a direct injection diesel engine using cashew nut shell oil as fuel with camphor oil blending, Energy. 47, 116-124 (2012)

[19] P.K. Devan, N.V. Mahalakshmi, A study of the performance, emission and combustion characteristics of a compression ignition engine using methyl ester of paradise oil-eucalyptus oil blends, Appl. Energy. 86, 675-680 (2009)

[20] R. Vallinayagam, S. Vedharaj, W.M. Yang, W.L. Roberts, R.W. Dibble, Feasibility of using less viscous and lower cetane (LVLC) fuels in a diesel engine: A review, Renew. Sustain. Energy Rev. 51, 1166-1190 (2015)

[21] E. Alptekin, M. Canakci, Determination of the density and the viscosities of biodiesel-diesel fuel blends, Renew. Energy. 33, 2623-2630 (2008) 